\title{
Lactonas Sesquiterpénicas aplicações farmacológicas e quimiotaxonómicas
}

\section{INTRODUÇÃO}

Nos últimos anos a Fitoquímica, ou Química das Plantas, desenvolveu-se como disciplina autónoma num campo intermédio entre a Bioquímica e a Química Orgânica. Ela diz respeito a uma enorme variedade de substâncias orgânicas, elaboradas e acumuladas pelas plantas, sua estrutura química, biossíntese, metabolismo, distribuição natural e também à sua função biológica.

Já que os metabolitos primários das plantas são objecto de estudo por parte dos Bioquímicos, os Fitoquímicos debruçam-se essencialmente sobre os metabolitos secundários, substâncias que, embora não tenham qualquer função aparente nos processos metabólicos essenciais, podem ser de enorme interesse, não só para a preservação das espécies vegetais, como também para aplicações fisiológicas ou farmacológicas.

Enquanto que a enorme variação química das vias metabólicas secundárias já é conhecida de há muito, só bastante recentemente se verificou que essa variação também se estende ao metabolismo primário das plantas (por exemplo, nos enzimas da respiração e nas vias fotossintéticas). Com esta descoberta de diversidade tanto nas moléculas pequenas como grandes do reino vegetal, os sistematas viraram-se para a Fitoquímica, como meio de aprofundar e clarificar o conhecimento das relações entre as plantas.

Recentemente os Fitoquímicos intensificaram o estudo das lactonas sesquiterpénicas, compostos que têm despertado enorme interesse, não só devido ao seu significado filogenético e quimiotaxonómico, como também devido à sua aplicação farmacológica. De facto, estas substâncias possuem, entre outras actividades, poder citostático, bactericida, fungicida e anti-inflamatório.

\section{ESTRUTURA E BIOSSÍNTESE}

As lactonas sesquiterpénicas são produtos naturais com quinze átomos de carbono, ou seus derivados, que teoricamente derivam da condensação de três fragmentos de isopreno (2-metil-1,3-butadieno). Estas unidades "C-5" são derivadas do ácido mevalónico que é o precursor utilizado pelas plantas na biossíntese de terpenos [1].

Existem quinze tipos de esqueletos básicos de lactonas sesquiterpénicas, podendo dizer-se que as germacranolidas, devido à sua origem biossintética, são o tipo mais primitivo destes compostos [2].
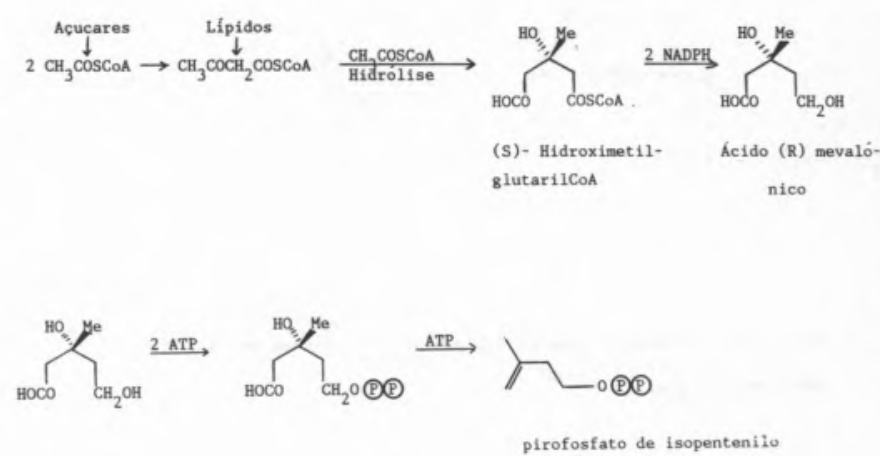

Biossintese das unidades C-5
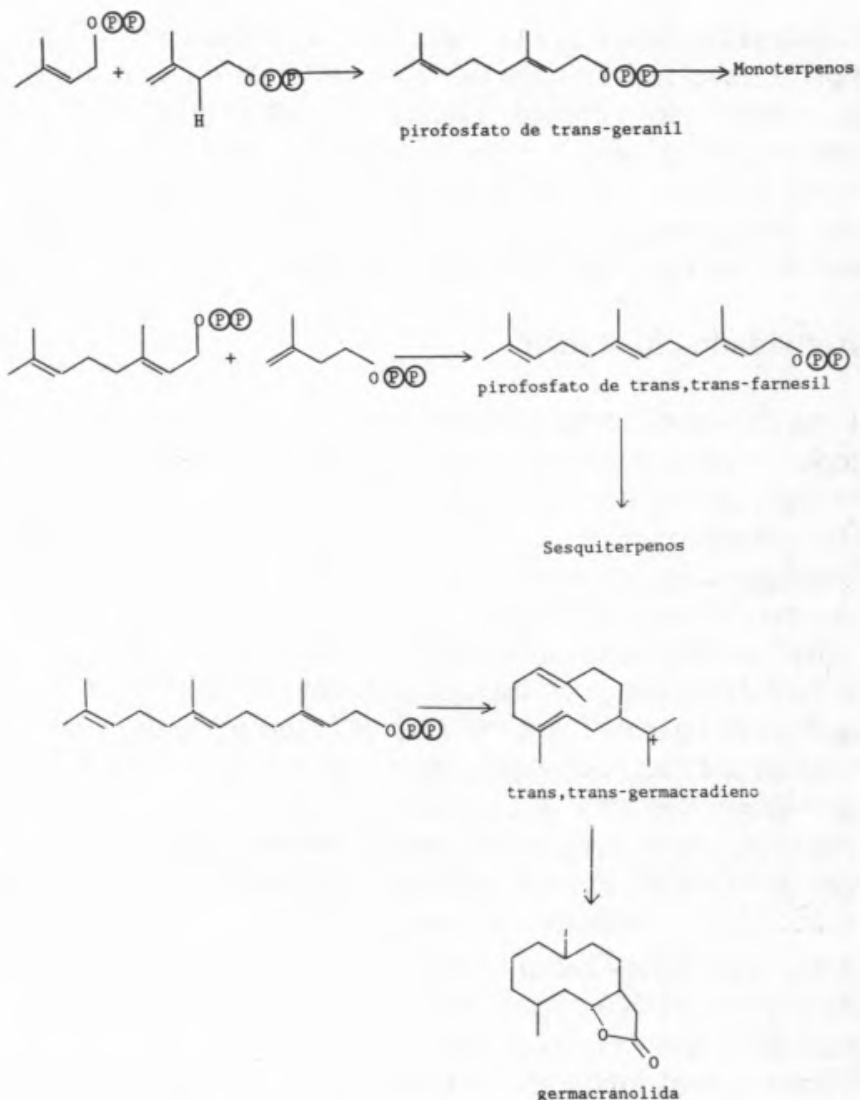

Biossintese de lactonas sequiterpénicas

a CECUL - Departamento de Química da Faculdade de Ciências de Lisboa, Instituto Bento da Rocha Cabral, Calçada Bento da Rocha Cabral, 14, 1200 Lisboa. 


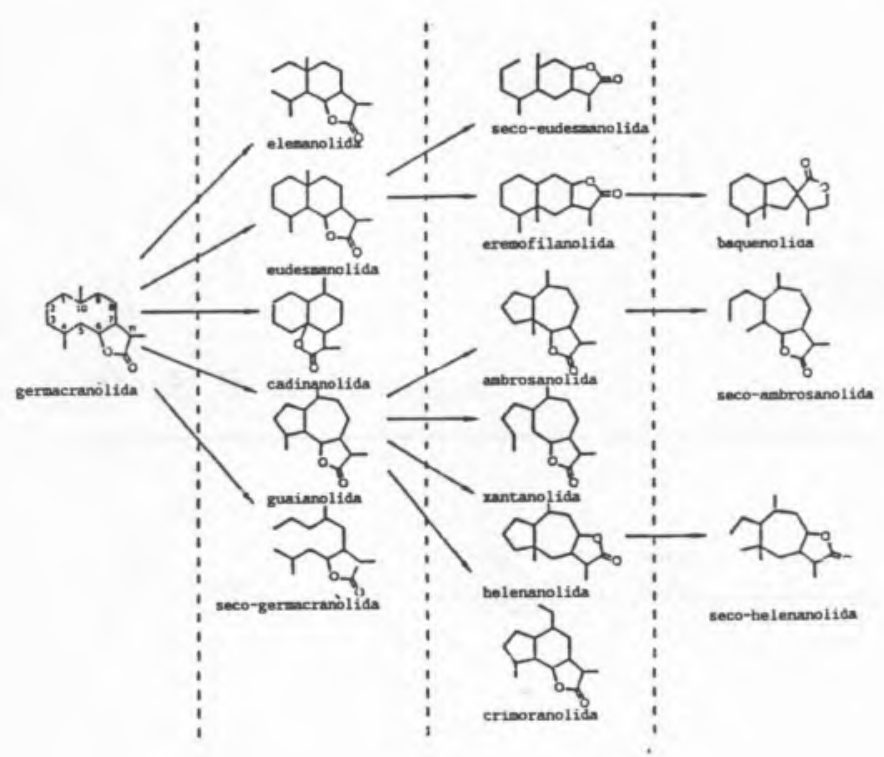

Esqueletos carbonados básicos, das principais classes de lactonas sesquiterpénicas.

\section{ACTIVIDADE BIOLÓGICA}

Como já foi dito, o grande interesse da procura destes compostos deve-se à sua actividade fisiológica e farmacológica. Além dos efeitos citostático, anti-inflamatório e microbiano já citados anteriormente, os quais irão ser tratados em pormenor, pode também referir-se que as lactonas sesquiterpénicas possuem igualmente propriedades anti-helminticas, anti-hiperlipidémicas e anti-ascaricidas.

\section{Actividade citostática}

Uma das descobertas mais interessantes em relação às lactonas sesquiterpénicas é a marcada actividade citostática que exibem alguns destes compostos. Assim, tem sido estudado o comportamento citotóxico de numerosas lactonas sesquiterpénicas, com especial incidência no efeito destes compostos na síntese de macromoléculas. Os primeiros resultados sobre o seu mecanismo de acção indicam a necessidade da presença de um agrupamento $-\mathrm{CH}=\mathrm{C}-\mathrm{C}=\mathrm{O}$, quer como parte de um éster, quer como parte de uma cetona ou lactona, como principal requisito à sua actividade anti-tumoral e citostática $[3,4]$.

Pensa-se que o mecanismo da citotoxidade seja do tipo adição de Michael, entre a parte activa da lactona e os grupos sulfidrilo dos enzimas lisossomais [5-9].

A inibição destes enzimas conduz por seu turno à inibição da síntese de DNA e, portanto, à diminuição do crescimento anárquico das células neoplásicas.

Contudo, uma hipótese alternativa para a actividade das lactonas sesquiterpénicas sugere uma alquilação directa do DNA por parte daqueles compostos [10].

No entanto, apesar de todas as esperanças depostas neste tipo de compostos como agentes anti-tumorais, a sua provável generalização e aplicação ao tratamento de neoplasias, está muito condicionado pelos seus efeitos citotóxicos gerais.

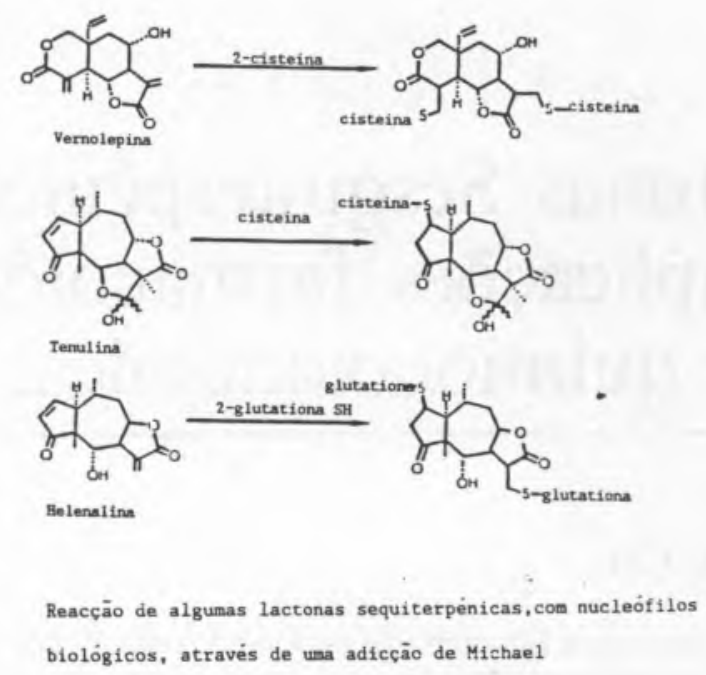

\section{Actividade bactericida e fungicida}

As lactonas sesquiterpénicas foram igualmente testadas como agentes bactericidas e fungicidas. Como anti-bacteriais mostraram ser particularmente activas contra bactérias Gram positivas, embora também possuam alguma actividade contra bactérias Gram-negativas [11-14].

Os estudos efectuados com o propósito de relacionar a estrutura química com a actividade bactericida, revelaram que esta última não pode ser explicada unicamente pela presença ou ausência do característico grupo exometilénico [15]. É provável que a actividade bactericida destes compostos seja determinada pela presença de vários grupos adicionais, da sua posição no esqueleto e da configuração dos grupos funcionais. A actividade de uma certa lactona pode também ser determinada pela existência, em bactérias específicas, de compostos vitais que possuam grupos tiol, ou afinidade química para a lactona.

Tal como para as bactérias, parece que a actividade fungicida das lactonas não pode ser explicada com base num único aspecto estrutural $[16,17]$. Pode ser necessária a presença de um ou mais centros activos para a actividade fungicida de algumas lactonas, ou estes podem reforçar a actividade de outros grupos funcionais. Igualmente a actividade contra os fungos pode ser determinada por diferenças de fisiologia das espécies individuais.

\section{Actividade anti-inflamatória}

A actividade anti-inflamatória das lactonas sesquiterpénicas é conhecida de há muito, já que plantas contendo aqueles metabolitos secundários têm sido utilizadas como medicamentos anti-piréticos e anti-inflamatórios. Estudos recentes $[2,18]$ demonstraram que muitas drogas anti-inflamatórias conhecidas, como a azotioprina e a D penicilamina, utilizadas no tratamento da artrite reumatismal, actuam do mesmo modo que as lactonas sesquiterpénicas, ou seja através dos grupos sulfidrilo dos enzimas. De facto, embora não se conheça ainda a exacta etiologia de muitos dos processos inflamatórios que atacam o homem, pensa-se que exista um envolvimento dos grupos sulfidrilo dos enzimas celulares. Assim, drogas que se liguem a estes grupos, bloqueando-os, revertem o processo inflamatório. 
Apesar dos estudos mecanísticos efectuados não serem de modo nenhum conclusivos, apontam mais uma vez para a necessidade da existência de um agrupamento $\alpha$-metileno- $\gamma$-lactona ou de um anel de ciclopentanona $\beta$ não substituída. Segundo alguns autores $[2,18]$ as lactonas sesquiterpénicas oferecem uma alternativa à terapia anti-inflamatória corrente, já que além das doses terapêuticas necessárias serem extremamente reduzidas, quando comparadas com as drogas comercializadas, não possuem quaisquer dos efeitos secundários tão comuns aos agentes anti-inflamatórios.

\section{Significado filogenético e quimiotaxonómico}

A taxonomia química, ou quimiotaxonomia, utiliza o conhecimento dos metabolitos secundários de um conjunto de organismos para determinar a sua posição numa escala evolutiva hierarquizada dos seres vivos. Ainda que na maioria dos casos, a quimiotaxonomia só venha confirmar as classificações dos taxónomos, é inquestionável que o acrescentar de informação química dos caracteres macro e micro morfológicos dos vegetais, só tornará mais segura as divisões taxonómicas.

A utilização dos tipos de esqueletos químicos na sistemática, pode resumir-se na seguinte sequência: um gene-um enzima-um passo biossintético-um composto.

As lactonas sesquiterpénicas, são precisamente uma classe de metabolitos secundários de interesse quimiotaxonómico, dado que, além de terem uma vasta distribuição nos vegetais superiores, possuem uma enorme variedade estrututal. o que facilita a sua identificação e correlação.

Estes compostos aparecem com frequência nas Umbelliferae e nas Compositae, sendo o tipo de esqueleto básico das lactonas uma característica da familia de plantas. Por exemplo, na tribo Helenieae encontram-se essencialmente guaianolidas, enquanto na tribo Senecioneae se encontram lactonas do tipo eremofilenoide e, nas Anthemidae, as lactonas são do tipo xantanólido, guaianólido e germacranólido. Recentemente foi efectuado um estudo sobre as relações filogenéticas entre as famílias Asteracea (Compositae) e Apiacea (Umbellifera), com base nas estereoestruturas das lactonas sesquiterpénicas presentes em ambas as famílias [18].

O estudo químico destas duas famílias levou a concluir que os esqueletos básicos das lactonas sesquiterpénicas nelas existentes são semelhantes, pertencendo ao tipo germacranolida, guaianolida, eudesmanolida, eremofilanolida ou helenanolida. No entanto, uma observação mais profunda das lactonas existentes nas duas famílias mostrou que a sua estereoquímica é diferente e, consequentemente, o seu grau de hidroxilação, esterificação e substituição também o é.
Estes factos apontam para um paralelismo biogenético na formação das lactonas sesquiterpénicas existentes nas duas famílias. Pensa-se que a separação dos passos biossintéticos se dá na formação no percursor C -15 da cadeia básica, conduzindo a conformações diferentes. No entanto, a diferença na estereo-construção de ambos os percursores não é tão grande que impeça um passo biossintético análogo para as lactonas sesquiterpénicas das duas famílias.

Pode concluir-se portanto que, em contraste com as outras interpretações correntes, as semelhanças existentes entre os caracteres e os metabolitos secundários das duas famílias não indicam uma convergência ou correlação evolutiva, mas tão somente um paralelismo biogenético. Posteriormente ambas se desenvolveram independentemente, encontrando-se neste momento em níveis diferentes de ramos evolutivos paralelos nas Angiospermicas. Ao mesmo tempo, estes estudos representam a confirmação de que existe uma consonância entre a ocorrência dos caracteres químicos e botânicos nestas duas famílias.

\section{Referências}

[1] A. M. Lobo "Biossíntese de Produtos Naturais - metabolismo secundário" (1976), Universidade Nova de Lisboa

[2] W.G. Ivie and D.A. Witzel in "Handbook of Natural Toxins", (1983), vol. II, pp. 543-584, R. T. Keeler and Tu, eds., Deker-New York [3] S.M. Kupchan, M.A. Eakin and A. M. Thomas, J. Med. Chem. (1971), 14, 1147

[4] K.H. Lee, H. Fumikawa and E. S. Huang, J. Med. Chem. (1972), 15,609

[5] I.H. Hall, K. H. Lee, C. O. Starnes, S.A. El Gaby, T. Ibuka, Y.S. Wu and M. Haruna J. Pharm. Sci. (1978), 67, 1235

[6] I.H. Hall, K. H. Lee, M. Okano, D. Sims, D. Ibuka, Y.F. Liou and Y. Imakura, J. Pharm. Sci. (1981) 70, 1147

[7] I.K. Hall, K.H. Lee, C.O. Starnes and T.G. Wadell, J. Med. Chem. (1977), 20, 233

[8] A.G. Gonzalez, V. Darias, E. Alonso e Esteves, Planta Med. (1980), 40, 179

[9] A.G. Gonzalez, V. Darias, G. Alonso, J. N. Boada and M. Feria Planta Med., (1978), 33, 356

[10] B.F. Abeysekera, Z. Abramowski and G.H.N. Towers, Biochem. Syst. Ecol. (1985), 13, № 3, 365

[11] J. Calzada, J.F. Ciccio and G. Echandi, Phytochemistry (1980), 19, 967

[12] K.H. Lee, T. Ibuka, R. Y. Wu and T.A. Geissman, Phytochemistry, (1977), 16, 1177

[13] K.H. Lee, T. Ibuka and R.Y. Wu, Chem. Pharm. Bull. (1974), 22, 2206

[14] A.K. Picman and G.H.N. Towers, Biochem. Syst. Ecol. (1983), 11, No 4, 321

[15] A.K. Picman, Biochem. Syst. Ecol. (1983), 11, № 3, 183

[16] A.K. Picman Biochem. Syst. Ecol. (1984), 12, № 12, 13

[17] I.H. Hall, K.H. Lee, C. O. Starnes, Y. Sumida, R.Y. Wu, T.G. Wadell, J.W. Cochran and K.G. Gerhart, J. Pharm. Sci. (1979), 68, 537 [18] M. Holub, J. Toman and V. Herout, Biochem. Syst. Ecol. (1987), 15 , No 3,321 


\section{Anestésicos *}

A anestesia é um termo, derivado do grego, que hoje é usado para descrever estados nos quais há perda de sensação, em particular aqueles estados produzidos por substâncias anestésicas.

Os anestésicos são quimicamente um grupo heterogéneo de fármacos e classificam-se segundo a sua acção em duas classes distintas: anestésicos gerais (que actuam no cérebro para produzir perda de consciência e consequentemente perda de todas as sensações) e anestésicos locais ( que actuam bloqueando a condução dos impulsos nos feixes das fibras nervosas).

\section{Anestésicos gerais}

Os anestésicos gerais são fármacos que deprimem de forma generalizada o sistema nervoso central e provocam perda de consciência. Usam-se em intervenções cirúrgicas, sob ventilação controlada, ou outros processos dolorosos, sós, ou, quase sempre, associados a outros fármacos, que provoquem a abolição da dor e o relaxamento muscular. O objectivo final da anestesia geral é, pois, a perda de consciência, a redução da actividade reflexa, deprimindo, não selectiva, mas reversívelmente o sistema nervoso central (SNC), a analgesia, e o relaxamento muscular esquelético, sem depressão respiratória ou cardiovascular.

Os compostos com actividade anestésica geral possuem uma grande diversidade química e, por isso, a sua classificação faz-se segundo as vias de administração, dividindo-se em dois grupos: anestésicos gerais de inalação (anestésicos voláteis) e anestésicos gerais intravenosos. Os primeiros são ainda subdivididos em: gases e líquidos voláteis (vapores). Os anestésicos gerais intravenosos são sólidos, administrando-se sob a forma de sais em solução. Na Tabela 1 estão indicados os anestésicos gerais mais importantes.

A anestesia geral está relacionada com uma alteração na trasmissão dos impulsos nos neurónios do SINC. O mecanismo para esta mudança não é completamente conhecido. Pode resultar do bloqueio dos canais de iões da membrana nervosa (muitos anestésicos reduzem o fluxo transmembranar). Pode estar relacionado com uma modificação não específica dos lípidos da membrana, pois a potência dos anestésicos gerais gasosos está estreitamente ligada à sua solubilidade nos lípidos das membranas. Por último, pode estar ligado a um efeito nos mecanismos neurotransmissores centrais. A sua acção pode ser descrita em estádios: estádio I - analgesia; estádio II - excitação; estádio III - anestesia cirúrgica; estádio IV depressão medular. Este comportamento deriva da diferente sensibilidade das várias zonas do SNC ao agente anestésico e, tradicionalmente é uma medida da profundidade da depressão. No entanto, com o uso dos anestésicos modernos estes estádios não são claramente observados devido à velocidade do seu efeito e aos seus efeitos irritantes mínimos.

\footnotetext{
a Faculdade de Farmácia de Lisboa.

* No artigo "ANESTÉSICOS» publicado no Boletim SPQ, 35, 29 (1989), por lapso, não foi inserida a introdução. Aqui a deixamos, com o pedido desculpas à autora e aos leitores.
}

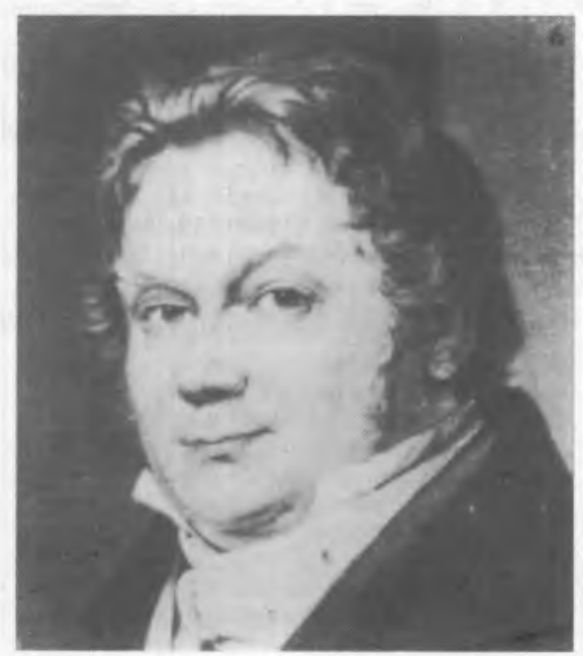

1829

BERZELIUS, Jacques, Barão (1779-1848)

Célebre químico sueco criador da Química moderna.

Temas: notação química; catá-

lise; teorià electrolítica.

\section{Descoberta do Tório por Berzelius, que assim o nomeou em honra do deus escandinávio Thor. A obtenção do elemento foi conseguida por reacção de óxido de tório com potássio.}

